\title{
Adult Patients who were Breastfed are Less Anxious but Suffer More Frequently of Non-Diarrheic Functional Bowel Disorders
}

\section{Michel Bouchoucha ${ }^{1,2^{*}}$, Ghislain Devroede ${ }^{3,4}$, Pierre Rompteaux ${ }^{2}$, Florence Mary ${ }^{2}$, Bakhtiar Bejou ${ }^{2}$ and Robert Benamouzig ${ }^{2}$}

\author{
${ }^{1}$ Université Paris Descartes, 15 Rue de l'école de Médecine, France \\ ${ }^{2}$ CEFRED (Centre d'Exploration Fonctionnelle et de Rééducation Digestive), Service de Gastroentérologie, \\ Hôpital Avicenne, France
}

${ }^{3}$ Département de Chirurgie, Faculté de Médecine, Université de Sherbrooke, Quebec, Canada

${ }^{4}$ Hôpital Fleurimont (CHUS), 300112 Avenue Nord, Sherbrooke, Canada

*Corresponding author: Dr. Michel Bouchoucha, Université Paris Descartes, 15 Rue de l'école de Médecine, 75270, Paris; CEFRED (Centre d'Exploration Fonctionnelle et de Rééducation Digestive), Service de Gastroentérologie, Hôpital Avicenne, 125 Rue de Stalingrad, 93000 Bobigny, France, Tel: 33-148957432, Fax: 33-148957437

\begin{abstract}
Introduction: Functional gastrointestinal disorders are pathologies of multifactorial origin. A shorter duration of breastfeeding has been found to enhance the prevalence of irritable bowel syndrome (IBS) in adulthood. The present observational study aims mainly to evaluate if breastfeeding is associated with IBS only or with other functional gastrointestinal disorders (FGIDs).

Patients and methods: 1106 consecutive FGID patients ( $70 \%$ female) aged $48.4 \pm 16.6$ years $(\mathrm{M} \pm \mathrm{SD})$, (BMI $26.9 \pm 11.0 \mathrm{~kg} / \mathrm{m}^{2}$ ) filled both a Rome III questionnaire, a psychological evaluation and a questionnaire about breastfeeding. The backwards selection procedure was used for model selection during multivariate logistic regression.

Results: Breastfed patients are older $(P=0.039)$, and have lower state anxiety $(\mathrm{P}=0.004 ; \mathrm{HR}=0.986 ; 95 \% \mathrm{Cl}=$ [0.976-0.995]). They suffer more frequently of IBS with constipation $(\mathrm{P}=0.028 ; \mathrm{HR}=1.866 ; 95 \% \mathrm{Cl}=[1.069-3.256])$, mixed IBS $(P=0.006 ; \mathrm{HR}=2.181 ; 95 \% \mathrm{Cl}=[1.254-3.792])$, functional constipation $(\mathrm{P}=0.006 ; \mathrm{HR}=1.909 ; 95 \% \mathrm{Cl}=$ [1.199-3.040]), and bloating ( $P=0.039 ; \mathrm{HR}=1.624 ; 95 \% \mathrm{Cl}$ $=[1.026-2.571])$. In contrast to esophageal, gastroduodenal and anorectal disorders which were not associated to the fact of having been breastfed or not.

Conclusion: Our results support the presence of an association between breastfeeding and non-diarrheic functional bowel disorders (IBS, IBS with constipation, mixed IBS, functional constipation and bloating) in FGIDs patients, but it also demonstrates that these people are less acutely anxious.
\end{abstract}

\author{
Keywords \\ Breastfeeding, Functional gastrointestinal disorders, Ir- \\ ritable bowel syndrome, Depression, Anxiety, Constipa- \\ tion, Bloating
}

\begin{abstract}
Abbreviations
FGID: Functional Gastrointestinal Disorders; BMI: Body Mass Index; IBS: Irritable Bowel Syndrome
\end{abstract}

\section{Introduction}

Many patients have persistent and recurring GI symptoms attributed to the digestive system. The Rome criteria [1], a classification of the functional gastrointestinal disorders (FGIDs) has been proposed, for FGIDS not associated to any structural or biochemical abnormalities. These disorders can affect any part of the GI tract (esophagus, stomach, colon, terminal intestine). FGIDs are not psychiatric disorders, although stress and psychological difficulties can make FGIDs worse. There are three primary features of FGIDs, namely motility, sensation and brain-gut dysfunction.

The prevalence of FGIDs in the general population is high: Functional dyspepsia 20 to $30 \%$, Irritable Bowel Syndrome (IBS) 10 to $20 \%$, functional constipation up to $27 \%$, pelvic floor dysfunction 5 to $11 \%$ [2]. More than 
half of subjects with FGID symptoms do not consult a physician, and take over-the-counter medications. These subjects also report significantly more job absenteeism and disability than healthy people [3]. Thus the high prevalence of a relatively benign problem is costly [4], those afflicted report power quality of life [5] and the search of a basic reason to these common dysfunctions remains very much in order $[6,7]$.

It has long been known that breastfed children are more resistant to infections (gastroenteritis, ear infections, etc.) than others [8]. This effect is linked to several immunological and non-immunological mechanisms. Secretory immunoglobulin (IgA, IgG and IgM), absent from the intestinal cells of newborn infants $[9,10]$, intact immune cells ( $B$ and $T$ lymphocytes, macrophages, leucocytes) as well as immunity-stimulating factors $[11,12]$ and non-immunological factors [13] can be found in the mother's milk. Recent studies have shown that nutrition has a major impact on early microbiota composition until cessation of breast-feeding, and is necessary for their maturation into adult-like microbiota [14].

$A$ recent study concluded that early environmental factors may play a role in the subsequent genesis of IBS [15]. The authors investigated 767 Australian subjects, and searched for the presence or not of IBS excluding organic diseases simply on the basis of self-reported rather than clinical investigation. They found that development of IBS was associated with childhood factors namely a shorter duration of breastfeeding, sharing a bedroom, exposure to herbivore pets and hygiene factors. Overall, they were extremely careful in their conclusion, wishing to rule out a type I error. They also investigated patients with functional dyspepsia, but they found no association with breastfeeding.

The aim of the present study was to evaluate if breastfeeding is associated with mood disorders and specific functional gastrointestinal disorders.

\section{Patients and Methods}

\section{Subjects}

From January 1, 2011 to December 31, 2014, 1205 outpatients were consecutively referred by gastroenterologists to our Center for Functional GI and Motility Disorders (CEFRED) (Centre d'Exploration Fonctionnelle et de Rééducation Digestive, Gastroenterology Clinic of the Avicenne Hospital), a tertiary center for FGID management. Among them, only 99 (9\%) were unable to specify whether or not they were breastfed, and excluded for this reason. The 1106 remaining patients with a full data set are included in the present study.

Before inclusion, a full evaluation had failed to yield any organic cause for the patients' complaint, although they were screened for bacterial overgrowth, eosinophilic colitis and connective tissue disorders. They also had morphological evaluation (endoscopy or ra- diology). Metabolic, endocrinologic, neurologic and psychiatric etiologies were excluded. Patients with drug addictions or previous digestive surgery, except cholecystectomy and appendectomy, were causes of exclusion from the study. A single investigator (MB) confirmed independently, during the medical visit, the validity of the initial diagnosis of FGID, and of all data mentioned above.

The study was declared in the French National Agency for drug safety (ANSM, Agence Nationale de Sécurité du Médicament et des produits de santé, decision number: 2015-A00954-45) and conducted according to the Declaration of Helsinki and Good Clinical Practice (GCP) guidelines.

\section{Experimental Procedure}

\section{Study design}

The comparison of the groups of FGID patients was performed within the framework of an observational study.

\section{Rome III questionnaire}

Patients in the gastroenterologist's office (MB) filled out a standard clinical questionnaire based on Rome III questionnaire [16]. The diagnostic process was previously described in published studies [17-19]. Functional esophageal disorders (heartburn, chest pain of presumed esophageal origin, dysphagia and globus) [20], functional gastroduodenal disorders (dyspepsia, postprandial distress syndrome, epigastric pain syndrome, belching disorders, aerophagia, unspecified excessive belching, nausea with or without, vomiting disorders, and rumination syndrome) [21], functional bowel disorders (Irritable bowel syndrome (IBS) and its subtypes (IBS with constipation (IBS-C), IBS with diarrhea (IBS-D), mixed IBS (IBS-M) and unsubtyped IBS (IBS-U), bloating, constipation, diarrhea, and unspecified) [1], abdominal pain syndrome [22], and anorectal disorders (fecal incontinence, functional anorectal pain, including levator ani syndrome and Proctalgia fugax, difficult defecation) [23], were diagnosed according to Rome III criteria. In addition regurgitation, soiling, and stool description using Bristol Stool Form Scale [1] were also recorded.

Finally, a question about breastfeeding ("Were you breastfed?" Answer "Yes" or "No"; not otherwise specified) was asked to all patients. This question has been asked all along because of the long known debate among pediatricians on a possible relationship between breastfeeding and constipation in babies [24,25].

\section{Psychometric evaluation}

Psychometric evaluation was focused on anxiety and depression. The level of depression was assessed by the French validated translation of the Beck Depression Inventory (BDI II) [26], frequently used in the evaluation of depression in gastrointestinal pathologies $[19,27]$. 
Anxiety was assessed by the French validated translation of the State and Trait Anxiety Inventory (STAI), made up of two axes ( $\mathrm{A} 1$ for state anxiety and $\mathrm{A} 2$ for trait anxiety) [28]. This test was selected for its simplicity, validity and reliability [29] and also because it was used to evaluate anxiety levels and to distinguish "state" anxiety from "trait" anxiety in gastrointestinal diseases [30,31].

\section{Statistical analysis}

Statistical analyses were carried out using IBM SPSS (IBM SPSS Statistics v20). Results are expressed as Mean and Standard Deviation. One-way ANOVA with Bonferroni's post-test was used to analyze quantitative variables and Chi square tests were used to analyze dichotomic variables.
Logistic regression was used for data analysis, systematically including age, gender, body mass index (BMI), depression, state and trait anxiety, functional gastrointestinal disorders as independent variables, and breastfeeding as dependent variable. The backwards selection procedure was used for model selection during multivariate logistic regression. Statistically significant variables $(P<0.05)$ remained in the adjusted model.

\section{Results}

There was a female predominance ( $70 \%$ female) in the population studied (Table 1). Patients had a mean age of $48.4 \pm 16.6$ years, and a BMI $26.9 \pm 11.0 \mathrm{~kg} / \mathrm{m}^{2}$. The mean duration of the symptoms was $12 \pm 10$ years (range 1 to 36 years).

Table 1: Demographics and clinical description of the population. Quantitative variables are expressed as mean \pm standard deviation and qualitative variables are expressed as number (percentage).

\begin{tabular}{|c|c|c|c|c|c|}
\hline & & All subjects & Breastfeeding & No breastfeeding & $P$ value \\
\hline \multirow[t]{4}{*}{ Demographics } & $\mathrm{N}$ & $1,106(100)$ & $454(41)$ & $652(59)$ & \\
\hline & Female patients & $778(70)$ & $330(73)$ & $448(69)$ & 0.087 \\
\hline & Age (years) & $48.4 \pm 16.6$ & $47.2 \pm 17.0$ & $49.3 \pm 16.2$ & 0.039 \\
\hline & $\mathrm{BMI}\left(\mathrm{Kg} / \mathrm{m}^{2}\right)$ & $26.9 \pm 11.0$ & $27.5 \pm 6.3$ & $26.5 \pm 13.3$ & 0.140 \\
\hline \multirow[t]{3}{*}{ Psychological } & Depression & $11.9 \pm 10.0$ & $11.5 \pm 9.4$ & $12.2 \pm 10.4$ & 0.284 \\
\hline & State anxiety & $39.9 \pm 12.8$ & $38.6 \pm 12.6$ & $40.7 \pm 12.9$ & 0.008 \\
\hline & Trait anxiety & $42.4 \pm 10.8$ & $41.8 \pm 10.5$ & $42.8 \pm 11.1$ & 0.125 \\
\hline \multirow[t]{5}{*}{ Esophageal } & Globus & $219(20)$ & $82(18)$ & $137(21)$ & 0.128 \\
\hline & Regurgitation & $145(13)$ & $50(11)$ & $95(15)$ & 0.051 \\
\hline & Chest pain & $303(27)$ & $117(26)$ & $186(29)$ & 0.173 \\
\hline & Heartburn & $363(33)$ & $140(31)$ & $223(34)$ & 0.134 \\
\hline & Dysphagia & $251(23)$ & $87(19)$ & $164(25)$ & 0.011 \\
\hline \multirow[t]{4}{*}{ Gastroduodenal } & Epigastric pain & $84(8)$ & $27(6)$ & $57(9)$ & 0.052 \\
\hline & Postprandial distress & $199(18)$ & $86(19)$ & $113(17)$ & 0.271 \\
\hline & Dyspepsia & $267(24)$ & $100(22)$ & $167(26)$ & 0.097 \\
\hline & Aerophagia & $286(26)$ & $112(25)$ & $174(27)$ & 0.247 \\
\hline \multirow[t]{8}{*}{ Bowel } & IBS (all subtypes) & $365(33)$ & $160(35)$ & $205(31)$ & 0.104 \\
\hline & IBS-Constipation & $54(5)$ & $28(6)$ & $26(4)$ & 0.066 \\
\hline & IBS-Diarrhea & $67(6)$ & $21(5)$ & $46(7)$ & 0.061 \\
\hline & IBS-Mixed & $56(5)$ & $30(7)$ & $26(4)$ & 0.036 \\
\hline & IBS Unspecified & $109(10)$ & $33(7)$ & $76(12)$ & 0.010 \\
\hline & Constipation & $80(7)$ & $43(9)$ & $37(6)$ & 0.012 \\
\hline & Diarrhea & $194(18)$ & $81(18)$ & $113(17)$ & 0.444 \\
\hline & Bloating & $83(8)$ & $41(9)$ & $42(6)$ & 0.069 \\
\hline Abdominal pain & & $122(11)$ & $49(11)$ & $73(11)$ & 0.457 \\
\hline \multirow[t]{6}{*}{ Ano-rectal } & Soiling & $96(9)$ & $34(7)$ & $62(10)$ & 0.143 \\
\hline & Fecal Incontinence & $87(8)$ & $39(9)$ & $48(7)$ & 0.262 \\
\hline & Levator ani syndrome & $69(6)$ & $27(6)$ & $42(6)$ & 0.420 \\
\hline & Proctalgia fugax & $58(5)$ & $21(5)$ & $37(6)$ & 0.265 \\
\hline & Non specific & $59(5)$ & $25(6)$ & $34(5)$ & 0.467 \\
\hline & Defecation disorders & $372(34)$ & $154(34)$ & $218(33)$ & 0.458 \\
\hline Bristol stool form & & $3.8 \pm 1.9$ & $3.8 \pm 1.9$ & $3.7 \pm 1.8$ & 0.608 \\
\hline
\end{tabular}

IBS: Irritable Bowel Syndrome. 


\section{Univariate analysis}

The patients who were breastfed were fewer than those who were not $(41 \%$ vs. $59 \% ; p<0.001)$, but younger $(P=0.039)$. The $B M I$ and the proportion of female patients are not different in breastfed and non-breastfed patients.

Among psychological parameters, state anxiety is lower in breastfed patients ( $38.6 \pm 12.6$ vs. $40.7 \pm 12.9$; $\mathrm{P}$ $=0.008$ ), whereas depression and trait anxiety are comparable in the two populations (Table 1).

Breastfed patients complain less frequently of dysphagia ( $P=0.011$ ), but the complaint of other esophageal disorders and gastroduodenal disorders are similar in the two groups (Table 1). Among bowel disorders, breastfed patients have more frequently mixed IBS ( $P$ $=0.010)$, unspecified IBS $(P=0.012)$, and functional constipation $(P=0.016)$. Among the other functional bowel disorders, IBS with constipation $(P=0.066)$, IBS with diarrhea $(P=0.061)$, and bloating $(P=0.069)$ show non-significant increase in breastfed patients (Table 1). The frequencies of anorectal disorders are also comparable in breastfed and non-breastfed patients.

\section{Multivariata analysis}

The multivariate analysis confirmed the positive association of breastfeeding with state anxiety $(P=0.004$; $\mathrm{HR}=0.986 ; 95 \% \mathrm{Cl}=[0.976-0.995])$, IBS with constipation $(\mathrm{P}=0.028 ; \mathrm{HR}=1.866 ; 95 \% \mathrm{Cl}=[1.069-3.256])$, mixed IBS $(\mathrm{P}=0.006 ; \mathrm{HR}=2.181 ; 95 \% \mathrm{Cl}=[1.254-$ 3.792]), functional constipation $(P=0.006 ; H R=1.909$; $95 \% \mathrm{Cl}=[1.199-3.040])$, and bloating $(\mathrm{P}=0.039 ; \mathrm{HR}=$ $1.624 ; 95 \% \mathrm{Cl}=[1.026-2.571])$.

\section{Discussion}

The present study demonstrates that patients who were breastfed are less anxious, but also have increased odds of presenting specific functional bowel disorders with delayed transit: IBS with constipation, mixed IBS, and functional constipation as well as bloating, while pathologies with shorter transit, i.e. diarrhea, IBS with diarrhea, upper FGIDs (esophageal, gastro-duodenal) and anorectal disorders are not associated to breastfeeding.

Breastfeeding does not protect against diarrhea, and favors delayed transit: Odds of constipation and odds of IBS with constipation are 1.9 fold increased. Yet, Bristol stool form was not different between breastfed and non-breastfed patients. Pediatricians often incriminate breastfeeding in the genesis of constipation in babies [24]. In tis study, the increased odds of bloating (3.5) could be interpreted as a result of the delayed transit. Indeed, previous studies have shown the importance of methanol production in constipated subjects [32-34]. In the present study, the methane production was not evaluated and further studies are needed to evaluate. In contrast, many studies on the importance of the mi- crobiota on FGIDs tend to enhance the importance of environmental factors [35-38].

Recent data have shown that childhood environment factors, particularly bedroom sharing and pet exposure are a risk factor for IBS in later life [15]. These authors also found that a shorter duration of breastfeeding was significantly associated with IBS as an adult, but they failed to identify the subtypes of IBS, such as defined by the Rome III group, thus lumping together patients with constipation and those with diarrhea, although these are clearly different psychologically $[19,39]$ and in terms of pathophysiology. Moreover, they also failed to recognize the fact that patients may evolve from functional constipation to IBS with constipation or vice-versa [40]. It is possible that behind these reasonably objective considerations on the importance, role and impact of breastfeeding, in terms of future digestive function, as part of modality of expression, there are much more basic different attitudes toward real or not difference between the old fashioned "biomedical" model of health and disease, and the more contemporaneous "biopsychosocial" model of medicine [41]. In short, that is the key question in all these studies including the present one.

Taking into account all possible variables including caring and maternal attitude [42], different elements may be at work during breast feeding, namely type of delivery, quality and type of maternal milk [43], its impact on the intestinal flora of the newborn baby [44], immunity as well as duration of breastfeeding [15], and use of antibiotics, etc. One must also consider all variables at work only after birth in view of mother-child attachment. Simply said, at the beginning of life, babies only have their body to speak out, and visceral somatization conceivably could be part of the process.

There are several methodological limits to the present study even if it confirms with a much larger group of patients, the study which demonstrated that environmental factors may play a role in the future occurrence -or genesis-of FGIDs [15], indeed, it does not take into account duration of breastfeeding, and changes in maturation of the baby's intestine over the first months of life. A second limit is the impossibility to assess the validity of a past history of breast feeding in adult patients. This limit was the same in previous published studies [15]. This objection could have been lifted by mother's interviews. Another limit is the absence of a healthy control group in the present study. However, it would be impossible to recruit two control cohorts of babies which are breastfed or not, follow them over decades and evaluate them subsequently for FGIDs, on the basis of the Rome criteria, established only in 2006, and make sure they do not have an underlying organic disease masked clinically as a gut dysfunction. One might also argue to have as 
basis of study a group of healthy subjects not suffering from FGID, referred according to a rigid algorithm defining the different types of FGID, and eliminating those not scoring positive for the Rome III criteria. Finally the question used didn't take into account the duration of breastfeeding [45], that could interact with the intestinal microbiota [46].

The previous study [15] investigating the potential influence of breastfeeding on future occurrence of FGIDs is entirely speculative when addressing the question of "hygiene hypothesis". We don't have data to support or not such hypothesis.

Breast-fed newborns have been demonstrated to carry a more stable and uniform microbiota population when compared to the formula-fed ones [47]. Breast milk can participate in the bacterial colonization of the breast-fed newborn [48]. The newborn is then continually exposed to new bacteria from the environment, food and skin bacteria from adults via feedings, petting or kisses. Once dietary supplementation begins, microbiota profile of breast-fed infants changes and between the first and the second year of life, differences between breast- and formula-fed infants are lost [49]. In addition, it was shown that breastfed could change the distribution of intestinal cells of Cajal in the small intestine and in the colon of a rodent model [50], and then alter the transit.

Another important aspect of breastfeeding is its psychological consequence for the mother as well as for the newborn. These become less anxious if breastfed. For the mother, postpartum depression is predicted by breastfeeding cessation and associated with shorter breastfeeding duration [51]. On the other hand, providing breast milk symbolizes embodied contact with their baby and increases maternal confidence [52]. All subjective and emotional exchange that may or not may occur between mother and child at that time, including all olfactive and gustative elements experienced by the baby. May carry an impact still visible during adulthood. It is not known if the psychosomatic separation or even dissociation has an impact on bowel function. It may possibly shed some light why a severe deleterious trauma such as sexual abuse, is found more often in the past history of patients with lower gastrointestinal dysfunction rather than in those with upper gastrointestinal dysfunction [53].

This study was performed in a tertiary center where patients consult for management of FGIDs, and are not a part of the general population. 99 patients were unable to indicate whether or not they were breastfed, but the high significance of our results allows to eliminate reasonably this parameter as a key factor. On the other hand, the relatively small number of breastfed patients $(41 \%)$ is lower than the actual frequency of breastfed subjects (74\%) in
France [45]. However, the frequency of breastfeeding found in the present study is in agreement with the mean age of the patients.

To conclude, breastfed patients suffered more from IBS-C, IBS-M, FC, and bloating and had lower "state" anxiety. In contrast, breastfeeding was not associated with esophageal, gastro-duodenalorano-rectal disorders. These results must be confirmed by further prospective studies.

\section{Authorship Statement}

$M B$ : Performed the research, contributed to the design of the study, performed data analysis, participated in the interpretation of data, wrote the article, revised the article for its content, and approved its final version; GD: Revised the article for its contentand approved its final version; PR: Participated in the selection of the patients and revised the article for its content; FM: Participated in the selection of the patients and revised the article for its content; BB: Participated in the selection of the patients and revised the article for its content; RB: Participated in the selection of the patients, contributed in the design of the study, revised the article's content and gave final approval for the version to be published.

\section{Competing Interests}

Michel Bouchoucha, Ghislain Devroede, Florence Mary, Pierre Rompteaux, Bakhtiar Bejou, Robert Benamouzig have no competitive interests.

\section{Funding}

No funding for this submission.

\section{Ethics}

The study was conducted in accordance with the Helsinki Declaration and was approved by the local medical ethics reviews board. Written informed consent was obtained from all patients.

\section{References}

1. Longstreth GF, Thompson WG, Chey WD, Houghton LA, Mearin F, et al. (2006) Functional bowel disorders. Gastroenterology 130: 1480-1491.

2. Drossman DA (2006) The functional gastrointestinal disorders and the Rome III process. In: Douglas A Drossman, Rome III: The functional gastrointestinal disorders. ( $3^{\text {rd }}$ edn), Degnon, McLean, VA, USA.

3. Ouyang A, Locke GR, 3rd (2007) Overview of neurogastroenterology-gastrointestinal motility and functional GI disorders: Classification, prevalence, and epidemiology. Gastroenterol Clin North Am 36: 485-498.

4. Talley NJ (2008) Functional gastrointestinal disorders as a public health problem. Neurogastroenterol Motil 1: 121-129.

5. Chang L (2004) Review article: Epidemiology and quality of life in functional gastrointestinal disorders. Aliment Pharmacol Ther 7: 31-39.

6. Deising A, Gutierrez RL, Porter CK, Riddle MS (2013) Post- 
infectious functional gastrointestinal disorders: A focus on epidemiology and research agendas. Gastroenterol Hepatol (NY) 9: 145-157.

7. Barbara G, De Giorgio R, Stanghellini V, Cremon C, Corinaldesi $R$ (2002) A role for inflammation in irritable bowe syndrome? Gut 1: 41-44.

8. Sankar MJ, Sinha B, Chowdhury R, Bhandari N, Taneja S, et al. (2015) Optimal breastfeeding practices and infant and child mortality:A systematic review and meta-analysis. Acta Paediatr 104: 3-13.

9. Biesbroek G, Bosch AA, Wang X, Keijser BJ, Veenhoven $\mathrm{RH}$, et al. (2014) The impact of breastfeeding on nasopharyngeal microbial communities in infants. Am J Respir Crit Care Med 190: 298-308.

10. Tow J (2014) Heal the mother, heal the baby: Epigenetics, breastfeeding and the human microbiome. Breastfeed Rev 22: $7-9$

11. Jelliffe DB, Jelliffe EF (1981) Breast milk and infection. Lancet 2: 419 .

12. Jarvinen KM, Aro A, Juntunen-Backman $K$, Suomalainen $H$ (1998) Large number of CD19+/CD23+ B cells and small number of CD8+ $T$ cells as early markers for cow's milk allergy (CMA). Pediatr Allergy Immunol 9: 139-142.

13. Hanson LA (1999) Human milk and host defence: Immediate and long-term effects. Acta Paediatr 88: 42-46.

14. Backhed F, Roswall J, Peng Y, Feng Q, Jia H, et al. (2015) Dynamics and stabilization of the human gut microbiome during the first year of life. Cell Host Microbe 17: 690-703.

15. Koloski NA, Jones M, Weltman M, Kalantar J, Bone C, et al. (2015) Identification of early environmental risk factors for irritable bowel syndrome and dyspepsia. Neurogastroenterol Motil 27: 1317-1325.

16. Whitehead WE, Validation Working Team in Association with the Rome Questionnaire Committee (2006) Development and validation of the Rome III diagnostic questionnaire. In: Drossman DA, Corazziari E, Talley NJ, Al e, Rome III: The functional gastrointestinal disorders. Degnon Associates, McLean, VA, USA.

17. Bouchoucha M, Fysekidis M, Devroede G, Raynaud JJ, Bejou B, et al. (2013) Abdominal pain localization is associated with non-diarrheic Rome III functional gastrointestinal disorders. Neurogastroenterol Motil 25: 686-693.

18. Bouchoucha M, Devroede G, Benamouzig R (2015) Are floating stools associated with specific functional bowel disorders? Eur J Gastroenterol Hepatol 27: 968-973.

19. Bouchoucha M, Hejnar M, Devroede G, Babba T, Bon C, et al. (2012) Anxiety and depression as markers of multiplicity of sites of functional gastrointestinal disorders: A gender issue? Clin Res Hepatol Gastroenterol 37: 422-430.

20. Galmiche JP, Clouse RE, Balint A, Cook IJ, Kahrilas PJ, et al. (2006) Functional esophageal disorders. Gastroenterology 130: 1459-1465.

21. Tack J, Talley NJ, Camilleri M, Holtmann G, Hu P, et al. (2006) Functional gastroduodenal disorders. Gastroenterology 130: 1466-1479.

22. Clouse RE, Mayer EA, Aziz Q, Drossman DA, Dumitrascu DL, et al. (2006) Functional abdominal pain syndrome. Gastroenterology 130: 1492-1497.

23. Bharucha AE, Wald A, Enck $P$, Rao $S$ (2006) Functional anorectal disorders. Gastroenterology 130: 1510-1518.

24. Mouterde O, Marie-Cardine A, Thiron JM, Mallet E (1999)
A propos de la "constipation" au lait maternel. Arch Pediatr 6: 229.

25. Choe YH, Lee JE, Moon KB, Hwang JH, Seo JM (2004) The infrequent bowel movements in young infants who are exclusively breast-fed. Eur J Pediatr 163: 630-631.

26. Beck AT, Steer RA, Brown GK (1998) BDI-II : Inventaire de dépression. ( $2^{\text {nd }}$ edn), du Centre de psychologie appliqué, Paris.

27. Sugaya N, Kaiya H, Kumano H, Nomura S (2008) Relationship between subtypes of irritable bowel syndrome and severity of symptoms associated with panic disorder. Scand J Gastroenterol 43: 675-681.

28. Spielberg CD, Gorsuch RL, Lushene RE, PR Vagg (1983) Manual for the state-trait anxiety inventory. Consulting Psychologist Press.

29. Grillon C, Ameli R, Foot M, Davis M (1993) Fear-potentiated startle: Relationship to the level of state/trait anxiety in healthy subjects. Biol Psychiatry 33: 566-574.

30. Addolorato G, Capristo $E$, Ghittoni G, Valeri C, Mascianà $R$, et al. (2001) Anxiety but not depression decreases in coeliac patients after one-year gluten-free diet: A longitudinal study. Scand J Gastroenterol 36: 502-506.

31. Spielberger CD (1993) Inventaire d'anxiété état-trait forme Y(STAI-Y). Bruchon-Schweitzer M, Paulhan I, Adaptation française de, Paris.

32. Triantafyllou K, Chang C, Pimentel M (2014) Methanogens, methane and gastrointestinal motility. J Neurogastroenterol Motil 20: 31-40.

33. Hwang L, Low K, Khoshini R, Melmed G, Sahakian A, et al. (2010) Evaluating breath methane as a diagnostic test for constipation-predominant IBS. Dig Dis Sci 55: 398-403.

34. Chatterjee S, Park S, Low K, Kong Y, Pimentel M (2007) The degree of breath methane production in IBS correlates with the severity of constipation. Am J Gastroenterol 102: 837-841.

35. Mayer EA, Savidge T, Shulman RJ (2014) Brain-gut microbiome interactions and functional bowel disorders. Gastroenterology 146: 1500-1512.

36. Ford AC, Quigley EM, Lacy BE, Lembo AJ, Saito YA, et al. (2014) Efficacy of prebiotics, probiotics, and synbiotics in irritable bowel syndrome and chronic idiopathic constipation: Systematic review and meta-analysis Am J Gastroenterol 109: 1547-1561.

37. Rajilic-Stojanovic M, Jonkers DM, Salonen A, Hanevik K, Raes J, et al. (2015) Intestinal microbiota and diet in IBS: Causes, consequences, or epiphenomena? Am J Gastroenterol 110: 278-287.

38. Levy RL, Jones KR, Whitehead WE, Feld SI, Talley NJ, et al. ( 2001) Irritable bowel syndrome in twins: Heredity and social learning both contribute to etiology. Gastroenterology 121: 799-804.

39. Bouchoucha M, Hejnar M, Devroede G, Boubaya M, Bon C, et al. (2014) Patients with irritable bowel syndrome and constipation are more depressed than patients with functional constipation. Dig Liver Dis 46: 213-218.

40. Wong RK, Palsson OS, Turner MJ, Levy RL, Feld AD, et al. (2010) Inability of the Rome III criteria to distinguish functional constipation from constipation-subtype irritable bowel syndrome. Am J Gastroenterol 105: 2228-2234.

41. Engel BT, Baile WF, Costa PT, Brimlow DL, Brinker J (1985) A behavioral analysis of chest pain in patients sus- 
pected of having coronary artery disease. Psychosom Med 47: 274-284.

42. Badinter $E$ (1982) L'amour en plus Histoire de l'amour maternel XVIlème-XXème siècle. Flammarion, Paris.

43. Marquis GS, Penny ME, Zimmer JP, Diaz JM, Marin RM (2003) An overlap of breastfeeding during late pregnancy is associated with subsequent changes in colostrum composition and morbidity rates among peruvian infants and their mothers. J Nutr 133: 2585-2591.

44. Eckburg PB, Bik EM, Bernstein CN, Purdom E, Dethlefsen $\mathrm{L}$, et al. (2005) Diversity of the human intestinal microbial flora. Science 308: 1635-1638.

45. Salanave B, de Launay C, Boudet-Berquier J, Castetbon K (2014) Durée de l'allaitement maternel en France (Épifane 2012-2013). Bull Epidémiol Hebd 27: 450-457.

46. Rautava S, Walker WA (2009) Academy of breastfeeding medicine founder's lecture 2008: Breastfeeding-an extrauterine link between mother and child. Breastfeed Med 4: 3-10.

47. Bezirtzoglou E, Tsiotsias A, Welling GW (2011) Microbiota profile in feces of breast- and formula-fed newborns by using fluorescence in situ hybridization (FISH). Anaerobe 17: 478-482.
48. Martin R, Jimenez E, Heilig $H$, Fernández L, Marín ML, et al. (2009) Isolation of bifidobacteria from breast milk and assessment of the bifidobacterial population by PCR-denaturing gradient gel electrophoresis and quantitative real-time PCR. Appl environ microbiol 75: 965-969.

49. Adlerberth I, Wold AE (2009) Establishment of the gut microbiota in Western infants. Acta Paediatr 98: 229-238.

50. Bellier S, Da Silva NR, Aubin-Houzelstein G, Elbaz C, Vanderwinden JM, et al. (2005) Accelerated intestinal transit in inbred mice with an increased number of interstitial cells of Cajal. Am J Physiol Gastrointest Liver Physiol 288: 151158.

51. Dias CC, Figueiredo B (2015) Breastfeeding and depression: A systematic review of the literature. J Affect Disord 171: $142-154$.

52. Swanson V, Nicol H, Mclnnes R, Cheyne $H$, Mactier $H$, et al. (2012) Developing maternal self-efficacy for feeding preterm babies in the neonatal unit. Qual Health Res 22: 1369-1382.

53. Leroi AM, Bernier C, Watier A, Hémond M, Goupil G, et al. (1995) Prevalence of sexual abuse among patients with functional disorders of the lower gastrointestinal tract. Int $J$ Colorectal Dis 10: 200-206. 